\title{
Combined effect of body mass index and metabolic status on the risk of prevalent and incident chronic kidney disease: a systematic review and meta-analysis
}

\author{
Jian Zhang ${ }^{12,3}$, Hong Jiang ${ }^{1,2,3}$ and Jianghua Chen ${ }^{1,2,3}$ \\ ${ }^{1}$ Kidney Disease Center, The First Affiliated Hospital, College of Medicine, Zhejiang University, Hangzhou, P.R.China \\ ${ }^{2}$ Kidney Disease Immunology Laboratory, The Third Grade Laboratory, State Administration of Traditional Chinese Medicine \\ of PR China, P.R.China \\ ${ }^{3}$ Key Laboratory of Multiple Organ Transplantation, Ministry of Health, Key Laboratory of Nephropathy, Zhejiang, P.R.China \\ Correspondence to: Jianghua Chen, email: chenjianghua@zju.edu.cn
}

Keywords: body mass index; obesity; metabolic status; chronic kidney disease; meta-analysis

Received: May 27, $2016 \quad$ Accepted: July 13, $2016 \quad$ Published: August 10, 2016

Copyright: Zhang et al. This is an open-access article distributed under the terms of the Creative Commons Attribution License (CC-BY), which permits unrestricted use, distribution, and reproduction in any medium, provided the original author and source are credited.

\section{ABSTRACT}

Objective: The risk of chronic kidney disease (CKD) differs in the normal weight, overweight, and obese individuals owing to metabolic abnormality. We aimed to determine the combined effects of body mass index (BMI) and metabolic status on the risk of the prevalence and incidence of CKD.

Methods: Pubmed, Scopus, Web of science, and abstracts from recently relevant meetings prior to April $\mathbf{2 0 1 6}$ were searched to identify eligible studies. Pooled relative risks (RR) and $95 \%$ confidence intervals (CI) were calculated using a random effects model.

Results: Eight cross-sectional studies and four longitudinal follow-up studies with a total of 14787 and 166718 participants were separately included in present study. Compared with metabolically healthy normal weight individuals, metabolically healthy obese individuals showed increased risk for CKD, with RR of 1.235 (95\%CI: 1.027 to 1.484 ), while metabolically health overweight individuals still presented in a healthy pattern, $R R=1.094(95 \% C I$ : 0.774 to 1.547$)$. In addition, metabolically abnormal groups had much higher risk for CKD, with RR of 1.572 (95\%CI: 1.373 to $1.801), 1.652(95 \% \mathrm{CI}: 1.139$ to 2.397$)$ and $1.898(95 \% \mathrm{CI}: 1.505$ to 2.395 ) across metabolically unhealthy normal weight, overweight and obese individuals respectively.

Conclusion: Individuals with abnormal metabolic status are at a significantly elevated risk for CKD, regardless of BMI. For metabolically healthy individuals, CKD risk increases with the growth of BMI, and obese persons eventually have a higher risk.

\section{INTRODUCTION}

Owing to its deadly adverse outcomes, including end-stage renal disease (ESRD) and increased cardiovascular risk, chronic kidney disease (CKD) has gradually became a major health burden worldwide [13]. As a consequence of lacking effective treatment for ESRD, devoting to identifying early risk factors of CKD is of great significance [4].

It has been well established that metabolic syndrome (MetS), a constellation of various metabolic abnormalities, is related to the development of CKD. Furthermore, the strength of association seems to increase along with the growth of the number of components of MetS [5].

Mounting evidence indicates that increased BMI is also associated with excess all-cause mortality and cardiovascular diseases [6]. Paradoxically, quite a few studies reported that obesity may confer a beneficial effect on individuals with chronic diseases [7-9]. Studies focused on the effect of obesity on the development of glomerulopathy generated discrepant results too [10-14]. Up to now, final conclusion has not yet been reached 
on such matters that if obesity itself without secondary metabolic abnormalities contributes to the development of CKD or whether the relationship between MetS and CKD differs along with weight change. The complexity of the relationship between $\mathrm{BMI}$ and $\mathrm{CKD}$ may presumably be attributed to the heterogeneity of obese phenotypes: presence or absence of concurrent metabolic abnormalities.

Combining obesity with different metabolic phenotypes generates the heterogeneity of obesity. Correspondingly, population can be divided into 6 subtypes: metabolically healthy with normal weight (MHNW), metabolically healthy overweight, metabolically healthy obese (MHO), metabolically abnormal with normal weight (MANW), metabolically abnormal overweight (MAOW), and metabolically abnormal obese (MAO) [15]. Among them, a clustering of risk factors including central adiposity, dyslipidemia, impaired fasting glucose, hypertension or insulin resistance (IR) has been defined as the MetS [16].

At present, existed studies yielded discrepant effects of obesity-metabolic subphenotypes on the risk of developing CKD. Additionally, data from these individual studies may be insufficient to demonstrate a possible differential risk for CKD.

So it is imperative for us to synthesize results of these related studies. Here, we first conducted a systematic review and meta-analysis of observational studies to determine the associations of BMI and the presence/ absence of metabolic abnormalities with the risk of prevalent and incident CKD.

\section{RESULTS}

Eleven studies met the inclusion criteria, of which three were cross-sectional studies [17-19], seven were longitudinal follow-up studies [20-26], and one study reported both follow-up data and prevalence of CKD [27]. A flow diagram of the study selection process was summarized in Figure 1. All studies were published in English. The total number of participants was 14787 and 166718 in cross-sectional and longitudinal studies respectively. Characteristics of included studies were shown in Table 1. For the present study, evaluating the follow-up outcome from eight longitudinal studies was the primary purpose. Seven of eight longitudinal studies chose incidence of CKD (eGFR $<60 \mathrm{ml} / \mathrm{min}$ per 1.73 $\mathrm{m}^{2}$ ) as the terminal event, while one study examined the joint associations of BMI and metabolic status with risk of ESRD (eGFR $<15 \mathrm{ml} / \mathrm{min}$ per $1.73 \mathrm{~m}^{2}$ ). Besides, three studies also reported the outcome of proteinuria separately. In the present review, we only pooled the outcome of development of eGFR $<60$ or $15 \mathrm{ml} / \mathrm{min}$ per $1.73 \mathrm{~m}^{2}$. The multivariate adjusted RRs and 95\% CI for the association between obesity-metabolic subphenotypes and incident CKD or ESRD risk was summarized.
Individual characteristics and prevalence of CKD were reported in four cross-sectional studies. Based on the definition of metabolically healthy and races of the included studies, distribution of MHO and MANW varied distinctly. Supplementary Table 1 shows the different distribution of participants in each group among studies.

\section{Obesity-metabolic subphenotypes and CKD risk}

A total of eight cohort studies were included for the analysis of incident CKD, of which one study reported the outcome of development of ESRD [21]. As Figure 2 shown, compared with metabolically healthy normal weight (MHNW), the pooled relative risks of CKD were extremely higher in metabolically unhealthy groups no matter companied with obese or not, with their RRs of 1.898(95\%CI: 1.505 to 2.395) (Figure 2C) and 1.572 (95\%CI: 1.373 to 1.801 ) (Figure 2B) separately. Furthermore, metabolically heathy obesity group were also at an increased risk estimate, with RR of 1.235 (95\% CI: 1.027 to 1.484 ), results displayed in Figure 2A. To further elaborate such effect, we restricted to three studies that presented detail data about overweight group. Likewise, metabolically abnormal overweight group had comparably elevated risk of CKD, with RR 1.652(95\%CI: 1.139 to 2.397) (Supplement Figure 1B); while in healthy overweight group, only a similar risk with MHNW group was observed) (Supplement Figure 1A).

Heterogeneity analysis was significant across the MHO group $\left(P=0.007, \mathrm{I}^{2}=65.8 \%\right)$; MHOW $(P=0.054$, $\left.\mathrm{I}^{2}=65.7 \%\right) ;$ MAO $\left(P=0.000, \mathrm{I}^{2}=78.6 \%\right)$ and MAOW $\left(P=0.063, \mathrm{I}^{2}=63.8 \%\right)$ respectively. There was no heterogeneity in the MONW group $\left(P=0.881, \mathrm{I}^{2}=0 \%\right)$.

The sensitivity analysis of incident CKD after eliminating one study every time yielded similar effect sizes in magnitude and direction to the overall estimates. After the study by Panwar in which ESRD was regarded as the endpoint was excluded, remained risk estimate was calculated, and results revealed that the relative risks of incident CKD were not significantly changed, except the overweight group (Supplement Figure 2). Additionally, heterogeneity disappeared across the MHO group ( $P$ $\left.=0.608, \mathrm{I}^{2}=0\right)$, but not in the MAO group $(P=0.000$, $\mathrm{I}^{2}=79.4 \%$ ). Likewise, the risk estimates did not differ remarkably and high heterogeneity continued to exist by removing other studies one by one across the MAO group. Therefore, we attempted to perform subgroup analyses to further explore the heterogeneity in the MAO group, on the basis of definition on MetS, study duration, number and races of participants (Supplementary table 2). However, significant heterogeneity remained.

Four cross-sectional studies reported the prevalence of CKD among MHNW, MHO, MANW and MAO populations at baseline. In the study of Wang, mildly reduced eGFR $\left(60-90 \mathrm{ml} / 1.73 \mathrm{~m}^{2}\right)$ was evaluated among 
Table 1: characteristic of cross-sectional studies and prospective cohort studies for the impact of obesity and metabolic abnormality on the prevalence and development of chronic kidney disease (eGFR $<60 \mathrm{ml} / \mathrm{min}$ per $1.73 \mathrm{~m}^{2}$ and/ or proteinuria)

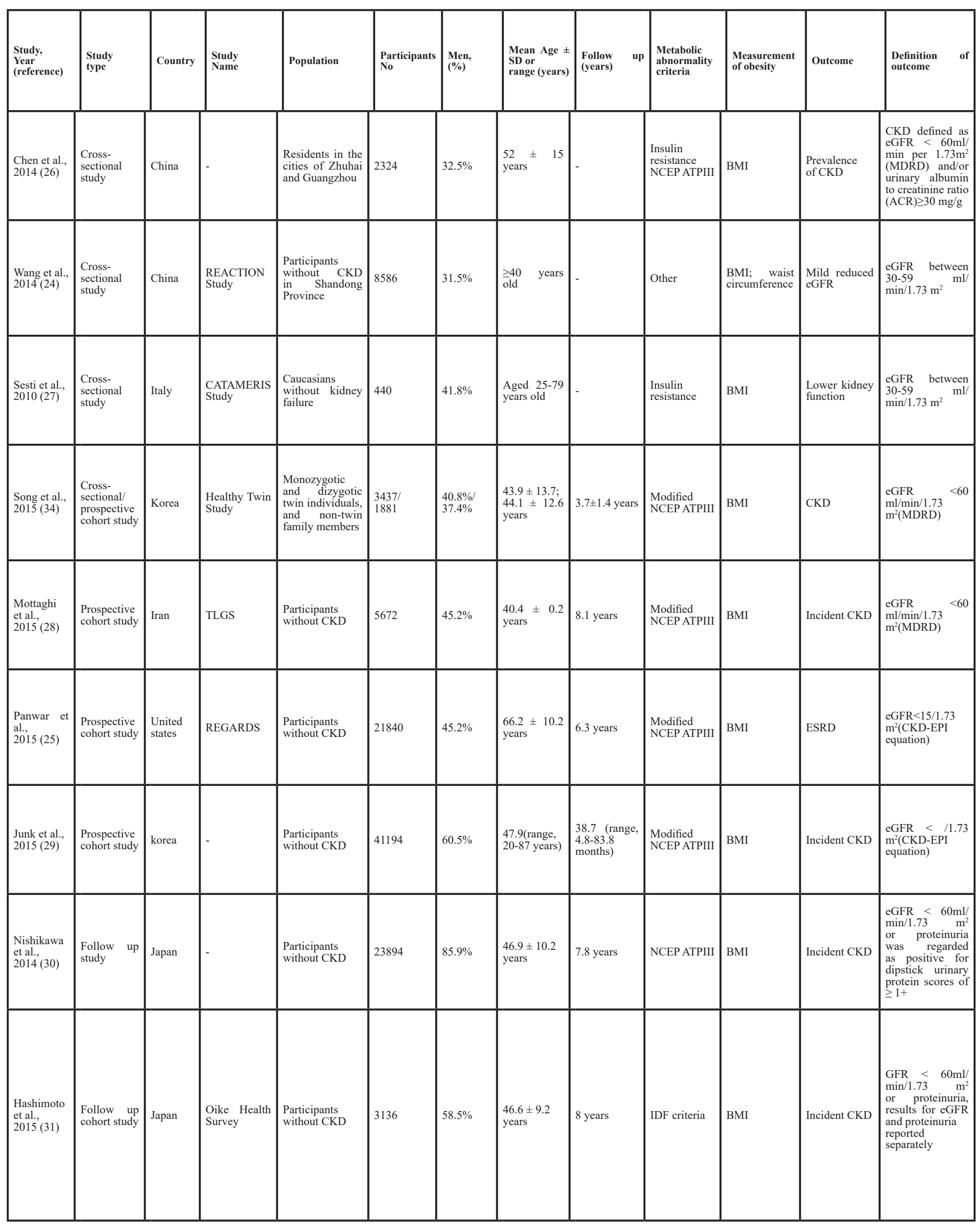




\begin{tabular}{|c|c|c|c|c|c|c|c|c|c|c|c|c|}
\hline $\begin{array}{l}\text { Cao et al., } \\
2015(32)\end{array}$ & $\begin{array}{l}\text { Cohort } \\
\text { study }\end{array}$ & China & - & \begin{tabular}{|l} 
Participants \\
without CKD
\end{tabular} & 6852 & $54.1 \%$ & $\begin{array}{ll}47 & (32-60) \\
\text { years }\end{array}$ & $\begin{array}{l}\text { Average } 54.3 \\
\text { months }\end{array}$ & $\begin{array}{l}\text { Modified } \\
\text { NCEP ATPIII }\end{array}$ & BMI & Incident CKD & $\begin{array}{l}\text { eGFR }<60 \mathrm{ml} / \\
\min / 1.73 \mathrm{~m}^{2} \text { or } \\
\text { proteinuria }\end{array}$ \\
\hline \begin{tabular}{|l|l} 
Chang et \\
al., \\
$2016(33)$
\end{tabular} & $\begin{array}{l}\text { Cohort } \\
\text { study }\end{array}$ & Korea & $\begin{array}{l}\text { The Kangbuk } \\
\text { Samsung } \\
\text { Health Study }\end{array}$ & $\begin{array}{l}\text { Metabolically } \\
\text { healthy } \\
\text { Participants } \\
\text { without CKD }\end{array}$ & 62249 & $50.5 \%$ & $\begin{array}{l}36.1 \pm 6.6 \\
\text { years }\end{array}$ & $\begin{array}{l}369088 \\
\text { person-years }\end{array}$ & $\begin{array}{l}\text { Insulin } \\
\text { resistance } \\
\text { modified } \\
\text { NCEP ATPIII }\end{array}$ & BMI & Incident CKD & $\begin{array}{l}\mathrm{e} G F R<60 \mathrm{ml} / \mathrm{min} \\
11.73 \mathrm{~m}^{2}(\mathrm{MDRR})\end{array}$ \\
\hline
\end{tabular}

Abbreviations: CKD, chronic kidney disease; ESRD, end stage renal disease; BMI: body mass index; NCEP-ATP III, National Cholesterol Education Program's Adult Treatment Panel III; IDF, International Diabetes Federation; MDRD, Modified Diet in Renal Disease; CKD-EPI, Chronic Kidney Disease Epidemiology Collaboration equation.

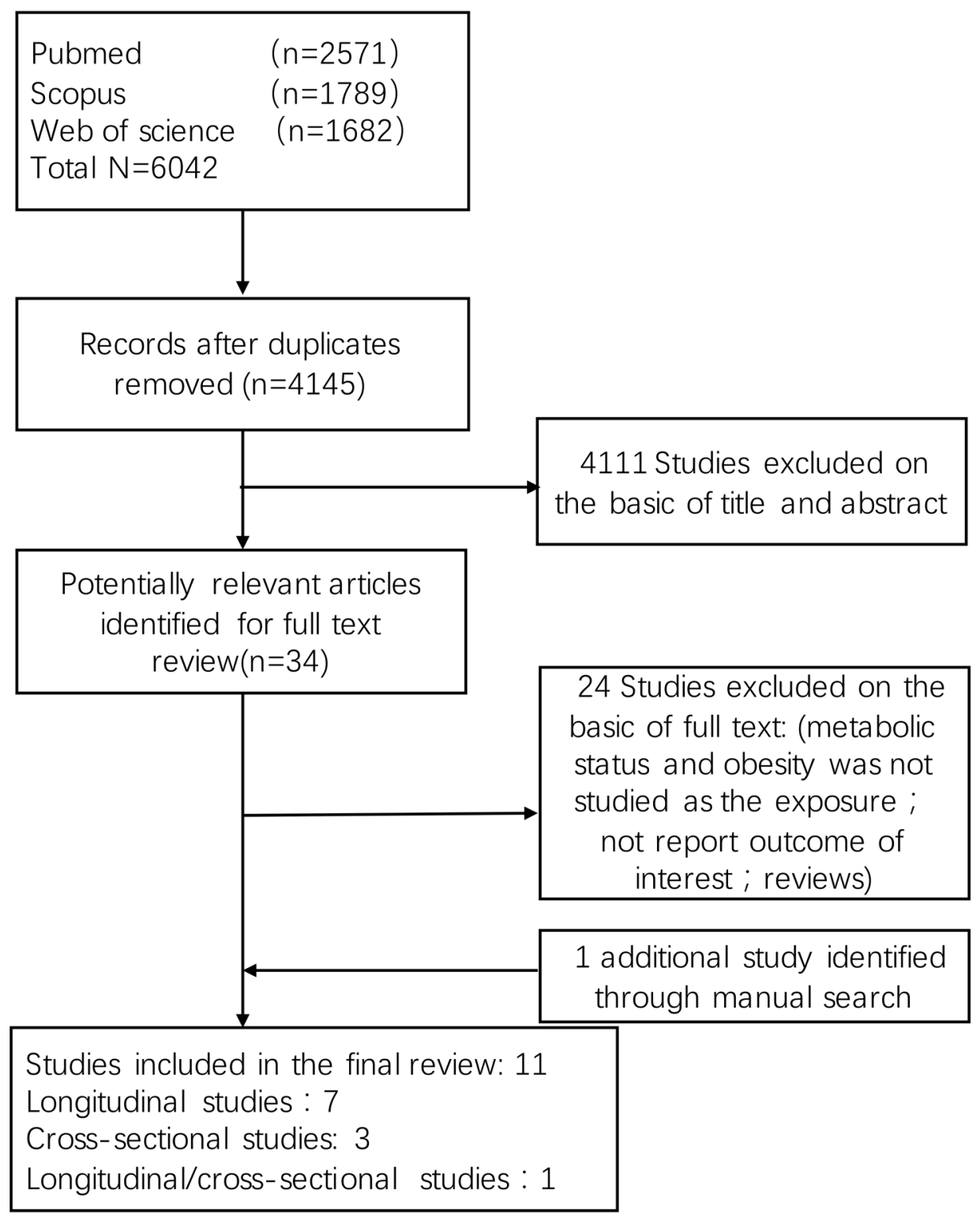

Figure 1: Flow diagram summarizing study identification and selection 
Table 2: Quality assessment of prospective cohort studies included in the systematic review

\begin{tabular}{|c|c|c|c|c|c|c|c|}
\hline Study, year(reference) & $\begin{array}{l}\text { Study } \\
\text { Participation }\end{array}$ & $\begin{array}{c}\text { Study } \\
\text { Attrition }\end{array}$ & $\begin{array}{l}\text { Prognostic } \\
\text { Factor } \\
\text { Measurement }\end{array}$ & $\begin{array}{l}\text { Outcome } \\
\text { Measurement }\end{array}$ & Confounding & Analysis & $\begin{array}{l}\text { Variables that were } \\
\text { Adjusted for }\end{array}$ \\
\hline Mottaghi et al. ,2015 & Yes & Partly & Yes & Yes & Partly & Partly & $\begin{array}{l}\text { basic Scr, age, sex, smoking, hypertension, and abdominal } \\
\text { obesity }\end{array}$ \\
\hline Panwar et al. ,2015 & Partly & No & Yes & Yes & Yes & Yes & $\begin{array}{l}\text { age, race, sex, geographic region of residence, education, } \\
\text { income, physical activity, current smoking, history of coronary } \\
\text { heart disease, and history of stroke }\end{array}$ \\
\hline Junk et al. ,2015 & Yes & Partly & Yes & Partly & Yes & Partly & $\begin{array}{l}\text { age and sex, baseline glomerular filtration rate, history of } \\
\text { cardiovascular disease, drinking, smoking, and exercise habits. } \\
\text { alanine aminotransferase, } \gamma \text {-glutamyltransferase, low-density } \\
\text { lipoprotein cholesterol, uric acid, and high-sensitivity C-reactive } \\
\text { protein }\end{array}$ \\
\hline Song et al. ,2015 & Partly & Partly & Yes & Partly & Yes & Partly & $\begin{array}{l}\text { sex, alcohol use, smoking amount, and physical activity at } \\
\text { baseline, household and sibling effects and sex }\end{array}$ \\
\hline Nishikawa et al. ,2015 & Yes & Partly & Yes & Partly & Yes & Unclear & $\begin{array}{l}\text { age, sex, smoking status, alcohol consumption, exercise habits, } \\
\text { walking time in commutation, type of work and occupational } \\
\text { exposure, C-reactive protein }\end{array}$ \\
\hline Hashimoto et al. ,2015 & Partly & Partly & Yes & Partly & Partly & Yes & age, sex, smoking statues, alcohol use \\
\hline Chang et al. ,2016 & Yes & Partly & Yes & Yes & Yes & Yes & $\begin{array}{l}\text { age, sex, study center, and year of screening examination, } \\
\text { smoking status, alcohol intake, and regular exercise }\end{array}$ \\
\hline Cao et al. ,2015 & Yes & Partly & Yes & Yes & Yes & Yes & $\begin{array}{l}\text { age, sex, smoking, plasma low-density lipoprotein cholesterol } \\
\text { level, medication use, and physical inactivity }\end{array}$ \\
\hline
\end{tabular}

different groups in middle-aged and elderly Chinese populations. Of which in the MHNW group, $19.21 \%$ of subjects had mildly reduced eGFR. In contrast, the corresponding proportions were $31.31 \%$ and $34.61 \%$ in MHO and MANW group. And there existed the highest increase in the proportion of mildly reduced eGFR (53.27 $\%)$ in the MAO group. Since we failed to obtain detail data of the study by Song after we tried to contact with authors, only the data from Chen and Sesti was pooled, with the overall prevalence of CKD in MHNW, MHO, MANW, MAO was $4.5 \%, 2.4 \%, 14.65 \%$ and $16.4 \%$ respectively. In summary, these findings were consistent with those from the above cohort studies in the general population.

\section{Study quality}

There exists quite obvious difference of study quality among included studies. The study quality for each individual domain is presented in Table 2. Almost all studies were at low risk for bias for prognostic factor assessment and confounding. On the contrary, the included studies had different risk profiles for other domains such as study participation, study attrition, outcome assessment, and study analysis.

\section{Publication bias}

No evidence of publication bias was detected in MHO, MHOW and MONW group on the basis of visual examination of the funnel plot or the Egger's test $(P=$ $0.71,0.486$ and 0.462 respectively) (supplementary Figure S3). Possible publication bias was detected in reporting of studies for the MAOW, MAO group with incident CKD risk ( $P=0.03$ and 0.032 respectively).

\section{DISCUSSION}

Recently, increasing interests have focused on the relationship between obesity-metabolic subphenotypes and various adverse events. Among them, there exist the biggest controversies over different outcomes in MHO group of obesity individuals who have relatively normal metabolic features and MANW group of metabolically unhealthy individuals whose BMI is in the normal level. Inconsistent effects of obesity-metabolic subphenotypes on the CKD risk were reported in various prospective longitudinal studies [28-31]. In addition, weight-loss intervention has also generated controversial results in some obesity-metabolic subtypes [32, 33].

So, the hypothesis that BMI combined with different metabolic states generate heterogenous CKD risk was 


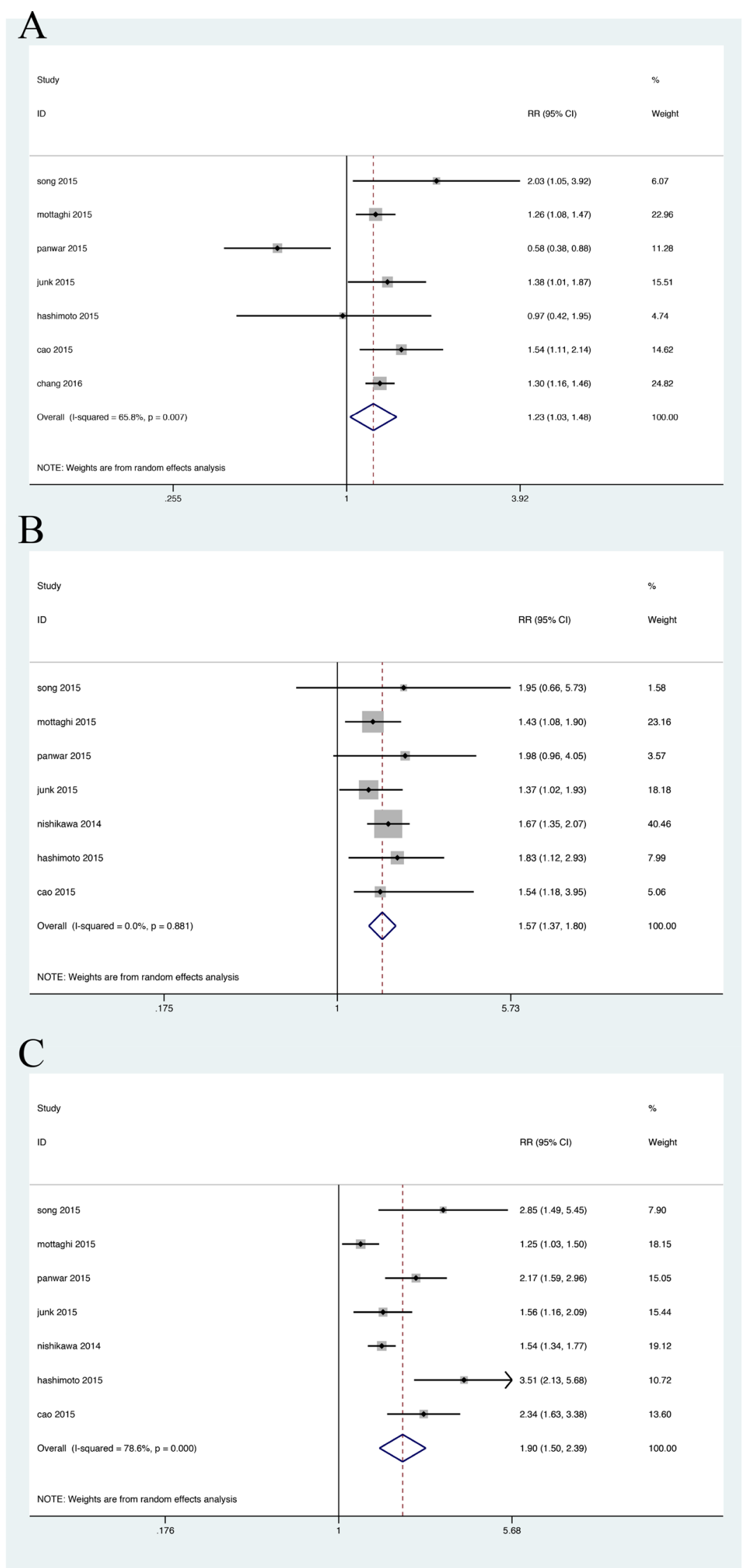

Figure 2: Relative risk of CKD in the obesity-metabolic subphenotypes. A. Metabolic healthy obese group; B. Metabolic abnormal with normal weight group; C. Metabolic abnormal obese group. 
addressed. Compared with MHNW persons, normal weight individuals with MetS and obese individuals at metabolically healthy status had significantly increased risk for incident CKD. As anticipated, obese people with MetS were at the highest risk of CKD. Only in the overweight group, different metabolic status led to discrepant risk for incident CKD. While remarkably elevated risk was found in MAOW individuals, it did not happen in overweight people with normal metabolic status.

Previous meta-analyses indicated that a higher BMI was associated with incrementally higher risk of kidney disease progress [34]. To some extent, these findings were in line with our results. But our analyses showed that overweight and even normal weight individuals may have higher risks for CKD if they stay in unhealthy metabolic status $(\mathrm{RR}=1.652(1.139-2.397) ; 1.572(1.373-1.801))$, compared with $\mathrm{MHO}$ individuals $(\mathrm{RR}=1.235(1.027-$ 1.484)). These inconsistent results demonstrated the importance of metabolic status involved in the effect of obesity on the CKD risk.

In terms of question whether healthy pattern of increased weight is involved in the development of CKD, our present study indicated that only MHOW individuals had no obvious elevated risk for CKD. Existed evidence demonstrated excess visceral adipose tissue could result in a feedback loop where obesity induced declines in kidney function lead to a further development of hypertension by activating the sympathetic nervous and renin-angiotensin systems [35]. Computed tomography and magnetic resonance imaging results also suggested that MHO individuals presumably had relatively lower levels of visceral adiposity and liver fat content [36, 37]. Another possible mechanism is associated with impaired mitochondrial biogenesis in adipocytes which are important contributors to energy balance and metabolic hemostasis. Low mitochondrial number and activity in adipose tissue has been suggested as underlying factors in MetS. And recent studies showed mitochondrial dysfunction was involved in obese-metabolic related diseases, as manifested in down regulation of mitochondrial biogenesis, oxidative metabolic pathways and OXPHOS proteins [38].

Our meta-analysis also showed that normal weight was unable to reverse the increased risk resulted from unfavorable metabolic status. Non-obese MS is considered to be characterized by body composition and fat distribution abnormalities (elevation of the visceral fat to subcutaneous fat ratio) as well as decreased insulin sensitivity [39]. Therefore, further identifying visceral adipose distribution condition will be of greater value for people with lifestyle-related diseases.

In addition, higher prevalence of CKD was observed in metabolically unhealthy group, especially in MAO individuals. But the conclusion can not be drawn so imprudently owing to the small number of cross-sectional studies.

\section{STRENGTHS AND LIMITATION}

Strengths of our present study include the large sample size which makes it possible to discriminate moderate differences among the BMI-metabolic subgroups and finally yields a convincing outcome. Both prospective cohort studies and cross-sectional studies were included and then analyzed separately in this meta-analysis, which gave a comprehensive understanding of the association between obese-metabolic subphenotypes and CKD risk.

Limitation of this study should not be ignored as well. Firstly, all of included studies used BMI to categorize normal weight, overweight and obesity. BMI might not be the best indicator for underlying adiposity [40]. So, it is indispensable for subsequent studies to evaluate the extent of visceral adiposity accumulation besides BMI to decrease the possibility of misclassifying and elevate study validity.

Secondly, observational studies involved in this meta-analysis may contain unknown confounding factors. The risk for bias varies from low to high for every individual domain. Just as other results from observational studies, associations do not imply causality certainly. However, the consistency of our results along with biologic plausibility highlights their correlation to clinical practice and, more significantly, can serve as elementary data for future interventional studies.

Thirdly, duration of exposure to the current BMI and metabolic factors, longitudinal changes in BMI and metabolic status during the follow up period was not illustrated in most studies. Nevertheless, the potential confounding is probably small considering the possibility of transition of individuals to higher weight categories is much larger than transition to lower weight categories.

Fourthly, lacking of uniform classification of BMI and standard definition of metabolic abnormality may be partly responsible for between-study heterogeneity. In the present study, $25 \mathrm{~kg} / \mathrm{m}^{2}$ was used as cut-point to distinguish obesity from normal weight individuals, for the majority of study populations come from Asia. Therefore, this result may not be fit for populations from other races. This needs to be further examined in subsequently large cohort studies based on other populations. Modified NECP ATPIII criteria was most commonly used in included studies, including increased central adiposity, elevated triglycerides, low HDL-C, hypertension and high fasting glucose. Besides, insulin resistance was also independently regarded as a sign of metabolic abnormality in partial studies [19]. It was unable to conduct subgroup analysis for studies adopted IDF criteria and insulin resistance separately. Therefore, we restricted analysis only to those studies use modified ATPIII criteria, finding results were similar with that when all studies were pooled.

Limitations in statistical analyses also need to be considered. First, unadjusted estimates from the study of Chang were pooled in our meta-analysis. Besides, 
covariates such as physical activity, smoking status, possibly associated with CKD risk failed to be included for analysis. Second, heterogeneity was not fully explained in MAO group. Consequently, results from these estimates should be interpreted discreetly. At last, we could not fully exclude publication bias in MHO group ,because we failed to get access to most unpublished results.

In conclusion, our present meta-analysis supports the opinion that the underlying heterogeneity for CKD risk exists in obese-metabolic subtypes. Except for MHOW individuals, obviously elevated risks for incident and prevalent CKD are observed in other obesity-metabolic groups. Moreover, all metabolically abnormal individuals are at a higher risk for CKD compared with corresponding healthy individuals. Thus, it is of great value to assess both BMI and metabolic status simultaneously for CKD risk estimate in high-risk populations. Relevant measures should also be made to prevent and control obesity and metabolic abnormality.

\section{MATERIALS AND METHODS}

This systematic review and meta-analysis is conducted in accordance with the Meta-analysis of Observational Studies in Epidemiology (MOOSE) guidelines [41] and was registered at International Prospective Register of Systematic Reviews (number CRD42016038886).

\section{Eligible criteria}

Studies were considered suitable for present metaanalysis if they met the requirement as below: conducted in adults; presented original cross-sectional or prospective data; evaluated participants according to categories of BMI, defined as normal weight (BMI $<25 \mathrm{~kg} / \mathrm{m}^{2}$ ), overweight (BMI 25-29.9 kg/m²), and obesity (BMI $\geq$ 25 or $30 \mathrm{~kg} / \mathrm{m}^{2}$ ); evaluated participants within these BMI categories according to different metabolic status (healthy or abnormal); and reported outcomes with prevalence and incidence of CKD, baseline characteristics, or all of above. Studies that were retrospective, did not stratify participants into the preceding 6 groups and lacked of valid data were excluded.

Due to the inconsistency across studies, we arbitrarily divided all participants into two groups primarily: defined normal BMI if it was identical or close to 18.5 to $24.9 \mathrm{~kg} / \mathrm{m}^{2}$, and obesity if it was equal or close to $\geq 25 \mathrm{~kg} / \mathrm{m}^{2}$. Then we further distinguished overweight from obesity group, assigned their values between 25 to $29.9 \mathrm{~kg} / \mathrm{m}^{2}$.

\section{Definition of metabolic syndrome}

We included studies that used the following definitions of metabolic syndrome (MetS): modified NCEP-ATP III criteria, IDF criteria, presence of insulin resistance and other (Supplementary table 3). According to the modified NCEP-ATP III criteria, metabolic syndrome was defined as having 3 or more of the following factors: (1)Elevated blood pressure: systolic/ diastolic blood pressure $\geq 130 / 85 \mathrm{mmHg}$ or ever received antihypertensive therapy; (2) Elevated triglyceride level: fasting triglyceride level $\geq 1.69 \mathrm{mmol} / \mathrm{L}(150 \mathrm{mg} / \mathrm{dl})$; (3) Decreased HDL-C level: HDL-C $<1.04 \mathrm{mmol} / \mathrm{L}$ (40 mg/ dl) in men or $<1.29 \mathrm{mmol} / \mathrm{L}(50 \mathrm{mg} / \mathrm{dl})$ in women or ever received lipid-lowering medication; (4) Elevated glucose level: fasting glucose level $\geq 5.6 \mathrm{mmol} / \mathrm{L}(100 \mathrm{mg} / \mathrm{dl})$ or ever received antidiabetic medication; (5) Obesity: waist circumference $>88 \mathrm{~cm}$ for women and $>102 \mathrm{~cm}$ for men. Insulin resistance was defined using the homeostasis model assessment (HOMA) [(fasting glucose $\times$ fasting insulin)/22.5]. A previously validated index (ISI) is derived from the OGTT [42].

\section{Data resources and search strategy}

We identified all studies that reported the associations of obesity and different metabolic status with the risk of prevalent and incident CKD from 1950 to April 2016. Pubmed, Scopus, Web of science and abstracts from 2013 to 2015 meetings of Endocrine society and the European society of Endocrinology were searched using optimally sensitive search strategies. Additionally, manual review of reference lists of all included articles was also performed. The following combined text word and MeSH were used: ("metabolic subtypes" or "obesity subtypes" or "metabolic phenotype*" or "obesity phenotype*" or "metabolically healthy" or "metabolically unhealthy" or "metabolic abnorma*" or "metabolically obese" or obesity or "over weight" or "body mass index") and ("chronic kidney diseases" or CKD or "End-Stage Kidney Disease" or ESRD), see Supplementary Search Strategy. All potentially eligible studies were retrieved and examined without the limit of languages. If the same cases were reported in more than one study, only the study with the most complete data was included.

\section{Data extraction and quality assessment}

Two investigators carefully screened titles and abstracts from all eligible studies for relevance. Discrepancies between investigators were solved by a third reviewer until a consensus was achieved. Extracted data included the first name of authors, year of publication, country, study name, features of study population (sample 
size, age, proportion of men, baseline characteristics of participants), duration of the follow-up, classification of study groups, definition of metabolically unhealthy, ascertainment of outcomes, numbers of prevalent and incident CKD. Adjusted risk estimates (hazard ratio or relative risk [RR] or odds ratio [OR]) were extracted for the following mergence and further analysis.

All included studies were assessed for quality according to previously published guidelines [43]. Risk of biases mainly focus on the following six domains: (1) study participation, (2) study attrition, (3) prognostic factor measurement, (4) outcome measurement, (5) confounding measurement, and (6) statistical analysis. Each of these individual domains was graded as "Yes", "Partly", "No" or "Unclear". The individual quality domain was categorized as low risk for bias (Yes) when complete information was reported to evaluate the study quality and the study reached the criteria for that quality domain, intermediate risk (Partly) was rated when the study reported inadequate data to assess that quality domain, and high risk (No) when it did not meet the criteria for that quality domain even if adequate data were reported. Studies without explicit description concerning the quality assessment were classified as "Unclear" and thus potentially at high risk for bias. Individual confounding factors adjusted in the multivariate analyses of the included studies were also covered in present study.

\section{Outcomes measures}

The following outcome measures were suitable for present study and analyzed separately: (1) prevalence of CKD $\left(\mathrm{eGFR}<60 \mathrm{ml} / \mathrm{min}\right.$ per $\left.1.73 \mathrm{~m}^{2}\right)$ using the Modified Diet in Renal Disease equation or CKD-EPI equation, with exception in the study by Wang [18], eGFR between $60-90 \mathrm{ml} / \mathrm{min}$ per $1.73 \mathrm{~m}^{2}$ was regarded as outcome. (2) development of eGFR $<60 \mathrm{ml} / \mathrm{min}$ per $1.73 \mathrm{~m}^{2}$ using the Modified Diet in Renal Disease equation or CKD-EPI equation, with exception in the study by Panwar [21], eGFR $<15 \mathrm{ml} / \mathrm{min}$ per $1.73 \mathrm{~m}^{2}$ was regarded as the event endpoint.

\section{Data synthesis and statistic analyses}

Overall relative risk was calculated to assess the risk of incident CKD. Multivariable-adjusted risk estimates of dichotomous data were pooled and RRs were presented using the random effects model with inverse variance weighting because of heterogeneity between studies. In addition, a pooled incidence rate of cross-sectional studies was calculated for the prevalence of CKD at baseline.

$\mathrm{I}^{2}$ inspection was carried out to determine the magnitude of the variance among included studies. If the values of $\mathrm{I}^{2}$ were larger than $50 \%$, moderate to extreme heterogeneity was judged. Next, subgroup analysis was conducted to explore the possible sources of variance among studies. Finally, we performed sensitivity by eliminating one study at a time and then calculated pooled relative risks for the residual studies to assess the degree to which the meta-analysis estimate depends on a particular study. The likelihood of publication bias was evaluated by using a funnel plot and the Egger's regression test. All tests were 2 -sided and $P$ value $<0.05$ was considered statistically significant. All analyses were performed using STATA version 13.0 software (STATA Corp, College Station, Texas, USA).

\section{CONFLICTS OF INTEREST}

No conflicts of interest exist for any authors.

\section{GRANT SUPPORT}

This work was supported by the National Fund Committee of China (2012CB517603, 2012AA02A512).

\section{Authors Contributors}

$\mathrm{ZJ}$ and $\mathrm{JH}$ contributed to conception and design of the study. ZJ and $\mathrm{JH}$ contributed to the data acquisition, analysis and interpretation of the data. $\mathrm{ZJ}$ and $\mathrm{JH}$ contributed to writing and editing the manuscript. All authors commented on drafts of the paper and have approved the final draft of the manuscript.

\section{REFERENCES}

1. Levey AS, Atkins R, Coresh J, Cohen EP, Collins AJ, Eckardt KU, Nahas ME, Jaber BL, Jadoul M, Levin A, Powe NR, Rossert J, Wheeler DC, et al. Chronic kidney disease as a global public health problem: Approaches and initiatives - a position statement from kidney disease improving global outcomes. Kidney international. 2007;72:247-259.

2. El Nahas AM, Bello AK. Chronic kidney disease. The global challenge. The Lancet. 2005;365:331-340.

3. Gansevoort RT, Correa-Rotter R, Hemmelgarn BR, Jafar TH, Heerspink HJL, Mann JF, Matsushita K, Wen CP. Chronic kidney disease and cardiovascular risk: Epidemiology, mechanisms, and prevention. The Lancet. 2013;382:339-352.

4. White SL, Cass A, Atkins RC, Chadban SJ. Chronic kidney disease in the general population. Advances in Chronic Kidney Disease. 2005;12:5-13.

5. Thomas G, Sehgal AR, Kashyap SR, Srinivas TR, Kirwan JP, Navaneethan SD. Metabolic syndrome and kidney disease: A systematic review and meta-analysis. Clinical journal of the American Society of Nephrology. 2011;6:2364-2373. 
6. Whitlock G, Lewington S, Sherliker P, Clarke R, Emberson J, Halsey J, Qizilbash N, Collins R, Peto R. Body-mass index and cause-specific mortality in 900000 adults: Collaborative analyses of 57 prospective studies. Lancet (London, England). 2009;373:1083-1096.

7. Beddhu S, Pappas LM, Ramkumar N, Samore M. Effects of body size and body composition on survival in hemodialysis patients. Journal of the American Society of Nephrology. 2003;14:2366-2372.

8. Kalantar-Zadeh K, Streja E, Kovesdy CP, Oreopoulos A, Noori N, Jing J, Nissenson AR, Krishnan M, Kopple JD, Mehrotra R, Anker SD. The obesity paradox and mortality associated with surrogates of body size and muscle mass in patients receiving hemodialysis. Mayo Clin Proc. 2010;85:991-1001.

9. Bashey S, Muntner P, Kini AS, Esquitin R, Razzouk L, Mathewkutty S, Wildman RP, Carson AP, Kim MC, Moreno PR, Sharma SK, Farkouh ME. Clustering of metabolic abnormalities among obese patients and mortality after percutaneous coronary intervention. The American journal of cardiology. 2011;107:1415-1420.

10. Gonzalez E, Gutierrez E, Morales E, Hernandez E, Andres A, Bello I, Diaz-Gonzalez R, Leiva O, Praga M. Factors influencing the progression of renal damage in patients with unilateral renal agenesis and remnant kidney. Kidney international. 2005;68:263-270.

11. Espinoza R, Gracida C, Cancino J, Ibarra A. Effect of obese living donors on the outcome and metabolic features in recipients of kidney transplantation. Transplantation proceedings. 2006;38:888-889.

12. Yamagata K, Ishida K, Sairenchi T, Takahashi H, Ohba S, Shiigai T, Narita M, Koyama A. Risk factors for chronic kidney disease in a community-based population: A 10-year follow-up study. Kidney international. 2007;71:159-166.

13. Kurella M, Lo JC, Chertow GM. Metabolic syndrome and the risk for chronic kidney disease among nondiabetic adults. Journal of the American Society of Nephrology. 2005;16:2134-2140.

14. Rashidi A, Ghanbarian A, Azizi F. Are patients who have metabolic syndrome without diabetes at risk for developing chronic kidney disease? Evidence based on data from a large cohort screening population. Clinical journal of the American Society of Nephrology. 2007;2:976-983.

15. Kwon BJ, Kim DW, Her SH, Kim DB, Jang SW, Cho EJ, Ihm SH, Kim HY, Youn HJ, Seung KB, Kim JH, Rho TH. Metabolically obese status with normal weight is associated with both the prevalence and severity of angiographic coronary artery disease. Metabolism: clinical and experimental. 2013;62:952-960.

16. Grundy SM, Brewer HB Jr, Cleeman JI, Smith SC Jr, Lenfant C. Definition of metabolic syndrome: Report of the national heart, lung, and blood institute/american heart association conference on scientific issues related to definition. Circulation. 2004;109:433-438.
17. Chen S, Zhou S, Wu B, Zhao Y, Liu X, Liang Y, Shao $\mathrm{X}$, Holthofer H, Zou H. Association between metabolically unhealthy overweight/obesity and chronic kidney disease: The role of inflammation. Diabetes Metab. 2014;40:423430 .

18. Wang C, Liang K, Zhang X, Li C, Yang W, Ma Z, Sun Y, Song J, Lin P, Gong L, Wang M, Liu F, Li W, et al. Metabolic abnormalities, but not obesity, contribute to the mildly reduced egfr in middle-aged and elderly chinese. International urology and nephrology. 2014;46:1793-1799.

19. Sesti G, Succurro E, Arturi F, Andreozzi F, Laino I, Perticone M, Sciacqua A, Hribal ML, Perticone F. Igf-1 levels link estimated glomerular filtration rate to insulin resistance in obesity: A study in obese, but metabolically healthy, subjects and obese, insulin-resistant subjects. Nutr Metab Cardiovasc Dis. 2011;21:933-940.

20. Mottaghi A, Mirmiran P, Delshad H, Azizi F. Effect of different obesity phenotypes on incidence of chronic kidney disease in tehranian adults. J Am Coll Nutr. 2015:1-10.

21. Panwar B, Hanks LJ, Tanner RM, Muntner P, Kramer H, McClellan WM, Warnock DG, Judd SE, Gutierrez OM. Obesity, metabolic health, and the risk of end-stage renal disease. Kidney international. 2015;87:1216-1222.

22. Jung CH, Lee MJ, Kang YM, Hwang JY, Kim EH, Park JY, Kim HK, Lee WJ. The risk of chronic kidney disease in a metabolically healthy obese population. Kidney international. 2015;88:843-850.

23. Nishikawa K, Takahashi K, Okutani $T$, Yamada R, Kinaga T, Matsumoto M, Yamamoto M. Risk of chronic kidney disease in non-obese individuals with clustering of metabolic factors: A longitudinal study. Internal medicine (Tokyo, Japan). 2015;54:375-382.

24. Hashimoto Y, Tanaka M, Okada H, Senmaru T, Hamaguchi M, Asano M, Yamazaki M, Oda Y, Hasegawa G, Toda H, Nakamura N, Fukui M. Metabolically healthy obesity and risk of incident ckd. Clinical journal of the American Society of Nephrology. 2015;10:578-583.

25. Cao X, Zhou J, Yuan H, Wu L, Chen Z. Chronic kidney disease among overweight and obesity with and without metabolic syndrome in an urban chinese cohort. BMC nephrology. 2015;16:85.

26. Chang Y, Ryu S, Choi Y, Zhang Y, Cho J, Kwon MJ, Hyun YY, Lee KB, Kim H, Jung HS, Yun KE, Ahn J, Rampal $\mathrm{S}$, et al. Metabolically healthy obesity and development of chronic kidney disease: A cohort study. Annals of internal medicine. 2016;164:305-312.

27. Song YM, Sung J, Lee K. Longitudinal relationships of metabolic syndrome and obesity with kidney function: Healthy twin study. Clinical and experimental nephrology. 2015;19:887-894.

28. Kramer CK, Zinman B, Retnakaran R. Are metabolically healthy overweight and obesity benign conditions?: A sysyematic review and meta-analysis. Ann Intern Med. 2013;159:758-69. 
29. Fan J, Song Y, Chen Y, Hui R, Zhang W. Combined effect of obesity and cardio-metabolic abnormality on the risk of cardiovascular disease: A meta-analysis of prospective cohort studies. Int J Cardiol. 2013;168:4761-4768.

30. Lee J, Ma S, Heng D, Tan CE, Chew SK, Hughes K, Tai ES. Should central obesity be an optional or essential component of the metabolic syndrome? Ischemic heart disease risk in the singapore cardiovascular cohort study. Diabetes Care. 2007;30:343-347.

31. Tong PC, Kong AP, So WY, Yang X, Ho CS, Ma RC, Ozaki R, Chow CC, Lam CW, Chan JC, Cockram CS. The usefulness of the international diabetes federation and the national cholesterol education program's adult treatment panel iii definitions of the metabolic syndrome in predicting coronary heart disease in subjects with type 2 diabetes. Diabetes Care. 2007;30:1206-1211.

32. Navaneethan SD, Yehnert H, Moustarah F, Schreiber MJ, Schauer PR, Beddhu S. Weight loss interventions in chronic kidney disease: A systematic review and meta-analysis. Clinical journal of the American Society of Nephrology. 2009;4:1565-1574.

33. Bolignano D, Zoccali C. Effects of weight loss on renal function in obese ckd patients. A systematic review. Nephrology, dialysis, transplantation. 2013;28 Suppl 4:iv82-98.

34. Wang Y, Chen X, Song Y, Caballero B, Cheskin LJ. Association between obesity and kidney disease: A systematic review and meta-analysis. Kidney international. 2008;73:19-33.

35. Aneja A, El-Atat F, McFarlane SI, Sowers JR. Hypertension and obesity. Recent progress in hormone research. 2004;59:169-205.

36. Kotronen A, Westerbacka J, Bergholm R, Pietilainen KH, Yki-Jarvinen H. Liver fat in the metabolic syndrome. The Journal of clinical endocrinology and metabolism. 2007;92:3490-3497.

37. Stefan N, Kantartzis K, Machann J, Schick F, Thamer C, Rittig K, Balletshofer B, Machicao F, Fritsche A,
Haring HU. Identification and characterization of metabolically benign obesity in humans. Arch Intern Med. 2008;168:1609-1616.

38. Heinonen S, Buzkova J, Muniandy M, Kaksonen R, Ollikainen M, Ismail K, Hakkarainen A, Lundbom J, Lundbom N, Vuolteenaho K, Moilanen E, Kaprio J, Rissanen A, Suomalainen A, Pietilainen KH. Impaired mitochondrial biogenesis in adipose tissue in acquired obesity. Diabetes. 2015;64:3135-3145.

39. Karelis AD, St-Pierre DH, Conus F, Rabasa-Lhoret R, Poehlman ET. Metabolic and body composition factors in subgroups of obesity: What do we know? The Journal of clinical endocrinology and metabolism. 2004;89:25692575.

40. Goodpaster BH, Krishnaswami S, Harris TB, Katsiaras A, Kritchevsky SB, Simonsick EM, Nevitt M, Holvoet P, Newman AB. Obesity, regional body fat distribution, and the metabolic syndrome in older men and women. Arch Intern Med. 2005;165:777-783.

41. Stroup DF, Berlin JA, Morton SC, Olkin I, Williamson GD, Rennie D, Moher D, Becker BJ, Sipe TA, Thacker SB. Meta-analysis of observational studies in epidemiology: A proposal for reporting. Meta-analysis of observational studies in epidemiology (moose) group. Jama. 2000;283:2008-2012.

42. Hanley AJ, Williams K, Gonzalez C, D’Agostino RB, Jr., Wagenknecht LE, Stern MP, Haffner SM. Prediction of type 2 diabetes using simple measures of insulin resistance: Combined results from the san antonio heart study, the mexico city diabetes study, and the insulin resistance atherosclerosis study. Diabetes. 2003;52:463-469.

43. Hayden JA, Cote P, Bombardier C. Evaluation of the quality of prognosis studies in systematic reviews. Ann Intern Med. 2006;144:427-37. 